\title{
A NAL Y IS
}

\section{or \\ FIFTY-TWO O CASES OF EPILEPSY}

\author{
OBSERVED BY THE AUTHOR.
}

(SECOND SERIES.)

BY

EDWARD H. SIEVEKING, M.D., F.R.C.P., PHYSIGIAN TO BT. MARY'S HOSPITAL.

Received Jan. 23rd-Read Feb. 12th, 1861.

IN 1857 the Medical and Chirurgical Society did me the honour to admit into their 'Transactions' an analysis of fifty-two cases of epilepsy which had been recorded by myself. I now again submit a similar analysis of a portion of the cases that have since been under my care, and I prefer taking the same number as on the former occasion, as it may be more convenient for comparison. The results yielded by the total number of the two series taken together may serve to rectify the inaccuracies which the smaller number of one series alone might appear to:involve. I may premise that I still hold epilepsy to present sufficiently characteristic features to justify our classing all cases of genuine epilepsy together, and treating them as dependent upon a depraved state of the nervous system common to all. As in the first series, I shall at present only dwell upon those points with reference to which satisfactory evidence could be obtained, avoiding matters of mere opinion, so as not to add to the theoretical difficulties which already 
surround the whole question. I shall also follow the same order of inquiry maintained on a former occasion.

Sex.-Of the fifty-two cases, twenty-three were females, or 44.2 per cent.; twenty-nine were males, or 55.8 per cent. This is very nearly the same proportion as in the first series, where the numbers were twenty-four females to twenty-eight males. If we take the two series together, the ratio of the females to males would be as $45 \cdot 2$ to $54 \cdot 8$, giving that preponderance to the male sex which is commonly supposed by British physicians to prevail.

Age.--The following table exhibits the distribution of the cases throughout the different periods of life, the basis of calculation being, as in the first series, not the age of. the patient when under treatment, but the age at which the epileptic paroxysm was first stated to have occurred.

\begin{tabular}{|c|c|c|}
\hline $\begin{array}{l}\text { Period of first } \\
\text { occurrence of fits. }\end{array}$ & Number of cases. & Ratio per cent. \\
\hline $\begin{array}{r}0-5 \\
6-10 \\
11-15 \\
16-20 \\
21-25 \\
26-30 \\
31-35 \\
36-40 \\
41-45 \\
46-50 \\
51-55 \\
56-68\end{array}$ & 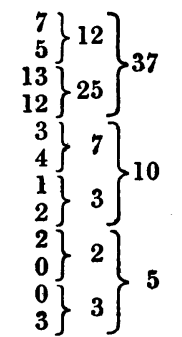 & $\begin{array}{l}71 \cdot 11\left\{\begin{array}{c}\text { From infancy to the age } \\
\text { of } 20 \text { years inclusive. }\end{array}\right. \\
19 \cdot 23\left\{\begin{array}{c}\text { From } 21 \text { to } 40 \text { years of age } \\
\text { inclusive. }\end{array}\right. \\
9 \cdot 61\left\{\begin{array}{c}\text { Prom } 41 \text { to } 68 \text { years of age } \\
\text { inclusive. }\end{array}\right.\end{array}$ \\
\hline
\end{tabular}

Here, again, we find a very close agreement with the results obtained by the former analysis, in which the ratios of the three corresponding divisions were respectively $69 \cdot 23$ per cent., 15.38 per cent., and 15.38 per cent. In the former series there was no case above the age of fifty-five, whereas, in the present, three are included in which epilepsy first made its appearance between fifty-six and sixty-eight years of age.

The confirmation which the former analysis gave to the 
views of Tissot and Esquirol, as to the greater proclivity of the male sex to epilepsy during puberty, is not renewed in the present instance. The following table gives the distribution of the cases according to sex, and it will be observed that, whereas there are eleven cases of males during the second decennium of life, there are fourteen females; while in the first series there were twelve males and seven females for the same period.

\begin{tabular}{|c|c|c|c|c|}
\hline \multirow{2}{*}{ Period. } & \multicolumn{2}{|c|}{ MaLes. } & \multicolumn{2}{|c|}{ Femalfas. } \\
\hline & $\begin{array}{l}\text { Absolute } \\
\text { number. }\end{array}$ & Per-centage. & $\begin{array}{l}\text { Absolute } \\
\text { number. }\end{array}$ & Per-centage. \\
\hline $\begin{array}{l}0-10 \text { years. } \\
11-20 " \\
21-30 " \\
31-40 " \\
41-50 \\
51-68 "\end{array}$ & $\begin{array}{r}8 \\
11 \\
5 \\
3 \\
1 \\
1\end{array}$ & \begin{tabular}{r|}
$27 \cdot 58$ \\
$37 \cdot 93$ \\
$17 \cdot 24$ \\
$10 \cdot 34$ \\
$3 \cdot 44$ \\
$3 \cdot 44$
\end{tabular} & $\begin{array}{r}4 \\
14 \\
2 \\
1 \\
2\end{array}$ & $\begin{array}{r}17 \cdot 39 \\
60 \cdot 86 \\
8 \cdot 69 \\
- \\
4 \cdot 34 \\
8 \cdot 69\end{array}$ \\
\hline
\end{tabular}

Causes.-An hereditary taint was traced with more or less certainty in fourteen cases, but the evidence in nearly half these cases indicated only a generally debilitating influence; in eight, epilepsy was found to have occurred in some relatives of the patient, but only in two had one of the parents been affected.

The following is a brief summary of the hereditary influences discovered in the fourteen instances :

1. The whole family are subject to nervous affections, hysteria, asthma, \&c.

2. The father died apoplectic, the mother was frightened by an epileptic patient while pregnant.

3. The mother was shocked by the suicide of a brother previous to the birth of the child, and suffered much in mind in consequence.

4. One sister has fits, and the parents are first cousins.

5. One sister died in fits as a child.

6. The mother and sister are hysterical and choreic. 
7. The mother and grandmother are epileptic.

8. Both parents died phthisical; the brothers and sisters died young.

9. A sister is epileptic.

10. A brother is epileptic.

11. The mother very excitable, and in a state of incipient insanity.

12. The mother and sister are epileptic.

13. Several cousins are subject to epilepsy.

14. The grandfather has had one or two fits late in life.

While an hereditary influence is undeniable, it does not appear, from the conjoint results of the two șeries, that it is traceable with anything like the same frequency as it is in some other morbid conditions, such as phthisis and gout; it is remarkable that the direct descent from parent to child was only noted in two instances. The difficulty of obtaining a positive clue as to the value of hereditary taint in these cases is much enhanced by the mystery with which all families try to shroud cases of epilepsy occurring in their members. In order to ascertain the real value of this predisposing cause, it would be necessary to be informed of the number of persons who are or have been epileptic, and whose progeny are affected with or are free from epilepsy. Although I have such cases in my note-books, they have only been obtained incidentally, and offer no indication as to the general ratio.

The exciting causes to which the fits were attributed by the patients, or which were ascertained by examination to have induced them, were elicited as follows :

Uterine derangement, 9 cases ; vencreal excesses, 6 cases ; fright, 4 cases; over-work, 4 cases; anxiety and dyspepsia, each 3 cases; dentition, 2 cases; scarlet-fever poison was accused, though doubtfully, twice ; while meningitis, anæmia, blood-poison, and the development of puberty, were each made responsible in onc case respectively. This list includes 37 cases; two more may be added in which the hereditary influence was supposed to be sufficiently strong to account for 
the seizures; this leaves thirteen in which no special predisposing or exerting cause was stated or traced.

Premonitory Symptoms. - The approach of the paroxysm was cognisable to the patient by certain symptoms, either perceptible to himself only, or visible also to those about him in twenty-one cases, or 40 per cent. In the former series, above one half, or 52 per cent., exhibited premonitory symptoms. In the cases under consideration they were as follows :

1. Pain in one or both temples. 2. Great fear. 3. Flushing for several hours before the attack, the latter being immediately preceded by a smacking of lips. 4. Fear. 5 . A sudden numbness of the head. 6. A peculiar sensation about the heart for five or six hours before. 7. Cross and peevish for a day before the fits. 8. Formerly a sense of dulness before the attacks. 9. Drowsiness and general langour. 10. Lassitude and biliary derangement. 11. A sense of terror, with formication in the right hand, and passing upwards. 12. Sleeplessness and anxiety. 13. Some consciousness of approach of fit. 14. Spasm of left arm and leg. 15. Creeping sensation from the tips of the fingers to the face, with spasms. of the muscles of the parts through which the sensation passes. 16. A sensation mounting up the left arm to the head. 17. An indescribable idea. 18. Vertigo and flashes. 19. Turgidity of the face for two days before the attack. 20. A horrible sensation. 21. A feeling of something closing the patient in, at times.

In regard to diagnosis, the presence or absence of a premonition offers no special indication; but it does as to treatment, and it is therefore an important feature. It enables us to ward off an attack, and also allows the patient to place himself in a position where he may escape injury during the seizure. Where the aura commences in an extremity, the fit may generally be prevented by suddenly constricting the limb above the point from which the sensation starts; or if it is a sensation affecting the viscera, the application of cold to the surface, or the administration of some internal remedy, frequently suffices to prevent the impending attack. 
Headache.-Headache is associated with epilepsy, either as a sequela of the attacks, as an habitual symptom, or as a precursor and a sequela. It was met with altogether in twenty-three out of the fifty-two cases, or in the ratio of $4.4 \cdot 2$ per cent. ; which is considerably less than in the former series, where the frequency of headache was 63.4 per cent.

The headache was constant or frequent in nine cases, or $17 \cdot 3$ per cent.

It occurred after the fits only in twelve cases, or 23 per cent.

It occurred only immediately before and after the fits in three cases, or $5 \cdot 7$ per cent.

It is manifest that the importance of this symptom must vary much, not only according to its severity, but more particularly according to the time at which it occurs. When affecting the patient habitually or frequently, it deserves much more serious attention as an indication of intracranial mischief, than when it appears only as a result of the vascular derangement induced by the fit itself. The bearing which it will have in influencing the treatment must vary accordingly.

Biting the tongue.-In the present series, twenty-eight patients were found to have bitten their tongue more or less frequently in the paroxysms, or 53.8 per cent. This is a larger proportion than in the former series, in which the ratio was $32 \cdot 7$. It is to be noted that in three of the cases this symptom was only observed in one fit, whereas in all the others it occurred frequently. The views of Schrôder von der Kolt regarding the limitation of the irritant in its action upon certain portions of the medulla oblongata, according to the presence or absence of the symptom in question, receive a general confirmation from my experience; at the same time, the fact of the tongue being bitten once, in cases in which this symptom does not otherwise accompany the fits, shows that the irritant cause may, at different times, involve different parts of the base of the brain.

Thinking that possibly the cases in which the tongue was not bitten might prevail among the female sex, and hence 
raise a suspicion of the hysterical element predominating, I analysed the cases with reference to this particular point; but the reverse of my anticipations resulted; for of the twenty-four cases in which there was no record of the tongue having been bitten, sixteen were males and eight females ; and whereas only one of the former left any doubt on the point, there were three among the latter in which the details of the cases being somewhat scanty, it is possible that the symptom was accidentally not adverted to.

Urine.-I have continued to examine the urine of epileptic patients, but have failed to detect any uniform derangement. Sugar I have never found, nor has there been in any of my cases either a constant or a frequent excess of phosphates or a diminution of urea; these being the features upon which previous observers have dwelt. So far from the urine being characterised by a frequent diminution of urea, I have in several cases met with a high specific gravity, ranging about 1030, in which there was a considerable excess of urea. In the present there was no case of albuminuria, excepting perhaps one instance in which a small quantity of albumen appeared to be present for a brief period. An excess of phosphates was seen twice. Oxalates were found in one or two cases, and a large deposit of lithates was also met with in a small number of cases; but although the treatment was varied according to these symptoms, none of them appeared with the frequency or uniformity which some writers would lead us to expect.

Among the symptoms referable to the abdominal organs, constipation and flatulency were certainly the most frequent, and seemed to depend upon that atonic habit which prevailed in most of my cases. The derangement of the chylopoietic viscera in some was so prominent, as almost to justify the view entertained by certain writers, that the sympathetic is the part of the nervous system most at fault in epilepsy; it was, however, on close examination always manifestly a concurrent effect of the fundamental lesion, rather than a fundamental lesion itself.

Treatment.-Under this head, I would reiterate the con. 
viction expressed in my former paper, that, however sceptical we may be in reference to permanent cures of epilepsy, we have just grounds for believing in the real efficacy of properly selected treatment in alleviating the disease, and often of indefinitely postponing the seizures. Perseverance and patience are demanded alike of the patient and the physician; but, above all things, it is necessary that the latter should have the full moral support of the patient and the patient's friends. The aid of the patient's friends is particularly a sine quâ non in the treatment of children and adolescents.

Many of the patients whose cases have been analysed in the present series have been seen in consultation, and have not therefore been continuously under my own observation; hence $I$ am enabled to give a positive statement of the results attained in only a part. I have reason to believe, after a considerable lapse of time, that eight were cured; decidedly benefited, fifteen; while the remainder were partly uninfluenced by treatment, or did not continue a sufficient period under observation to justify any statement as to the result. I find that sixteen of the cases were seen only once or twice, which must be borne in mind in estimating the effect of treatment.

As I have neither discovered nor believe in the existence of a specific for epilepsy, and as I do not profess any method of procedure not already employed by physicians, I refrain from going into detail in this paper as to treatment. I adhere to my formerly expressed view as to the necessity of an eclectic treatment, selected according to the features of each individual case. In epilepsy, specialism is to be particularly avoided, and I hold that the physician who enjoys the best general knowledge of his profession will also be best qualified to deal with this particular affection. 